Fecha de recepción: julio 2012 Fecha de aceptación: febrero 2013 Versión final: marzo 2014

\section{Claves de identidad del programa Identidades Productivas}

Marina Porrúa ${ }^{*}$

Resumen: Diseño Colectivo, Identidad, Diversidad , Articulación y Red, son las claves que identifican al programa Identidades Productivas, de la Secretaría de Cultura de la Nación, que, solidariamente con el "Plan de Capacitación en Diseño: Producir redes para potenciar recursos, proyectos e identidades", de la Universidad Nacional de Mar del Plata, promueven, desde 2002, el desarrollo de grupos dedicados al diseño y producción colectiva de sistemas de objetos, portadores de identidades culturales, con rango de Colección provincial y/o nacional.

Palabras clave: articulación - cultura - diseño colectivo - diversidad - educación - identidad - red.

[Resúmenes en inglés y portugués en la página 140]

(*) Arquitecta (UNMdP). Es Profesora Titular Regular de la materia Diseño 1 y Profesora Adjunta Regular del Taller Vertical de Diseño de Indumentaria 2/ 3/ 4, en la Carrera de Diseño Industrial, Faud, UNMdP. Desde 2002 a la fecha, desarrolla Extensión con Transferencia, siendo Directora del Grupo de Extensión “Cultura y Diseño”. Es autora y coordina académicamente, junto a la Arq. Marta Rueda, el programa "Capacitación en Diseño para la Producción: producir redes para potenciar recursos, proyectos e identidades", propuesta pedagógica del Programa "Identidades Productivas", de la Secretaría de Cultura de Nación.

Desarrollar la cultura en las sociedades contemporáneas, multiculturales y densamente interconectadas, no puede consistir en privilegiar una tradición, ni simplemente preservar un conjunto de tradiciones unificadas por un Estado como "cultura nacional". El desarrollo más productivo es el que valora la riqueza de las diferencias, propicia la comunicación y el intercambio -interno y con el mundo- y contribuye a corregir las desigualdades (García Canclini, 2005, pp. 2-3).

El Programa Identidades Productivas, de la Secretaría de Cultura de la Nación, solidariamente con el "Plan de Capacitación en Diseño: Producir redes para potenciar recursos, proyectos e identidades", elaborado por el Grupo de Extensión "Cultura y Diseño" de la Facultad de Arquitectura, Urbanismo y Diseño, de la Universidad Nacional de Mar del 
Plata, busca generar y desarrollar, en las provincias argentinas, grupos dedicados al diseño y la producción colectiva de sistemas de objetos, con rango de Colección Provincial y/o Nacional, portadores de identidades culturales.

Desde sus inicios en 2002, a la fecha, este programa se ha ido perfeccionando y adaptando, en función de la experiencia transcurrida, trascendiendo, siempre, las expectativas iniciales. Actualmente pueden sintetizarse 2 grandes etapas:

La Etapa 1, se concentra en la conformación de un colectivo de diseño provincial, para la generación de un sistema de objetos con identidad, de autoría compartida.

Este objetivo, de escala provincial, ha sido desarrollado, a lo largo de 10 años, en 12 provincias argentinas. La Pampa, Santa Cruz, Chubut, San Juan, Mendoza, Río Negro, Santiago del Estero, Jujuy, Formosa, Chaco, Corrientes y Tierra del Fuego poseen sistemas de objetos con rango de Colección con Identidad Provincial.

La Etapa 2, consistente en la articulación de los colectivos provinciales en uno de mayor escala, lo que ha dado lugar, recientemente, a la constitución de la Red Identidades Productivas, colectivo interprovincial, que desarrolló las bases para una colección de objetos con identidad argentina, desde la construcción de un relato de identidad nacional, concebido desde una visión federal. A la par, se busca consolidar procesos de producción, comercialización y promoción de su colección Argentina en el Bicentenario, desarrollada mancomunadamente entre los 680 capacitados.

El proceso desarrollado es complejo y rico en construcción. Hay atesorado en este desarrollo grandes virtudes que generaron -y siguen generando- un particular compromiso de las instituciones provinciales y nacionales y de los colectivos provinciales capacitados, hoy conformados como red creativa, productiva y de comercialización. La primera de ellas, fue la inclusión de la diversidad social y cultural, como un eje para el desarrollo de la cultura, esa cultura que se hace entre todos, desde la producción humana como símbolo de supervivencia pero también de identificación plural.

La producción de la cultura -de los objetos culturales- es mucho más que el mero hecho de elaboración. Implica un acto creativo y de representación. Creación, elaboración y representación están en la raíz del acto productivo, del emprendimiento humano, de su hacer cultural. Esta impronta no sólo viene dada por el mensaje que los objetos transportan, sino, además, por la inclusión de diseño en un sistema de objetos de propiedad colectiva. Éstos se gestan y emergen desde procesos de articulación de las personas, con sus identidades, y las habilidades técnicas específicas, que son capaces de movilizar para transformar la materia con la que cuentan, de una manera posible, legítima y efectiva, promoviendo un nuevo sentido de innovación para la sustentabilidad.

El diseño se constituye en el marco ético que permite articular aspectos económicos, ambientales, sociales, y culturales, de las personas, los productos y del sistema en que este funciona, promoviendo la mejora de la calidad de vida de todos los participantes y su comunidad. Todo ello conforma un tránsito hacia una productividad artesanal y semiindustrial, ecológicamente sustentable, surgida como cuestionamiento a la economía de mercado y las tecnologías dominantes, intentando poner en valor un uso más racional de los recursos naturales y culturales, considerando la complejidad y diversidad socioambiental y recuperando la ética como valor de equidad. 
La observación sistemática y crítica del camino recorrido y de sus resultados, ha permitido abstraer las claves esenciales que definen su identidad:

- Diversidad

- Identidad

- Articulación

- Diseño Colectivo

- Red...

\section{Diversidad}

Si bien Identidades Productivas es un programa nacional, es el estado provincial, a través de sus instituciones, quien realiza la convocatoria, que se extiende a todos los municipios. El perfil del grupo estará signado por el tipo de problemas que cada provincia busque resolver, por ejemplo, hacer competitiva la artesanía; sacar las artesanías del rango de souvenir, promoviendo su valor de uso para la vida contemporánea; plantear a la artesanía como un punto de partida para generar desarrollos productivos más complejos; generar productos con identidad que acompañen programas de fomento del turismo; resolver problemas de inclusión o integración en sectores o grupos frágiles, como pueden ser las comunidades originarias; fomentar el uso de materiales locales; rescatar técnicas olvidadas; aumentar la calidad de determinadas producciones; generar un sello provincial; promover nuevos vínculos entre personas e instituciones, etc.

En general, los grupos se componen de artesanos independientes, grupos pertenecientes a las comunidades originarias (en aquellas provincias en que los hay, se presentan a la capacitación como comunidad o como familias: abuelos, padres e hijos), artistas visuales, docentes de arte y artesanía, pequeños productores, grupos productivos consolidados o en vías de consolidación, profesionales diversos y, además, todos aquellos que quieran sumarse a un proyecto de creación y producción de objetos con identidad local. Resulta siempre significativa la cantidad de personas jubiladas, que buscan iniciar un nuevo proyecto productivo en donde, además de mantenerse activos, puedan contribuir con su experiencia. El perfil de la convocatoria es siempre inclusivo y amplio, dando como resultado un heterogéneo humano (en edad y género), racial, cultural y social.

La Capacitación en Diseño, dictada en modalidad de laboratorio/ taller constituye el espacio de interacción de la multiculturalidad, por lo tanto las relaciones culturales que se plantean entre los participantes responden a esa diversidad. El grupo con el que se trabaja es un pequeño recorte que representa la composición social y cultural de la provincia. Cuando uno enseña tiene dos opciones posibles, trabajar con la diversidad misma o buscar homogeneizarla, reproduciendo, para ello, un modelo preconcebido, dominante o unitario, como sea, ajeno a la realidad que se observa o, por lo menos, no el único. El grupo docente, responsable, opta por la multiculturalidad, fomentando la interacción y el diálogo como un camino a la pluricultura y, en definitiva, también, a la pluriidentidad. El taller se convierte, así, en un campo de producción y creación de cultura, dominado 
por las tensiones, desigualdades, rivalidades, estados de conflictividad propios de cada provincia. Desencuentro cultural y social que se resuelve con el diálogo. El rol docente en este diálogo es fundamental, si puede asumirse como un articulador de lo diverso. Como se verá más adelante, la articulación como procedimiento, es pertinente -y fructíferapara poner en relación cosas, personas, culturas distintas, sin pretender homogeneizar ni subordinar.

Dice García Canclini que:

...la Argentina es un país constitutivamente multiétnico, formado por poblaciones indígenas -que subsisten en el noroeste, en el Chaco y en la Patagonia- y diversas migraciones europeas..." (podríamos agregar aquí la árabe, entre otras) “...con diferencias notables entre sus regiones. Pero también conocemos que es un hábito argentino tratar de olvidarlo (García Canclini, 1999, p. 215).

Hacer memoria de lo que está olvidado o velado, entonces, es una actividad esencial a la hora de desentrañar las identidades que deberán articularse en un sistema de objetos de creación colectiva.

Es el diálogo mismo el que permite comenzar a correr el manto del olvido (o del ocultamiento). Ese plano raso, por que fue "arrasado", que entierra el recuerdo del exterminio, en la provincia de La Pampa. O la resistencia y reclusión final de las etnias originarias en el Impenetrable Chaqueño -espacio mítico, de reserva natural para la supervivencia continental en tiempos de la precolonia- lo que significó, finalmente, su confinamiento en un espacio de "inclusión para la exclusión" definitiva, eso que, por analogía, el filósofo italiano Giorgio Agamben denomina "campo de concentración", espacio en el que queda suspendida la democracia, en virtud de una estructura jurídico política operada en el escenario.

Haciendo un recorrido por las publicaciones que institucionalizan las luchas por los derechos de los pueblos originarios de América, se ve cómo, sistemáticamente, los conflictos, levantamientos, cortes de ruta, etc. tienen como objetivo final el diálogo. Desde la recuperación de esta práctica milenaria, que les permite el reconocimiento del otro, buscan ser tenidos en cuenta como parte constitutiva del tejido socio- cultural y político contemporáneo, en sus escalas provincial, nacional, continental y/o internacional. Es el reclamo que la diversidad le hace al mundo global, a su homogeneidad abstracta.

"El diálogo debe convocarnos hacia el reencuentro de pueblos, sociedades y culturas. Si quinientos años hemos vivido juntos pero de espaldas, es necesario mirarnos de frente y reconocernos en el diálogo". (Macas, 2001, p. 7).

Este "mirarnos de frente" para "reconocernos", es la práctica obligada, en el primer seminario de capacitación, en aquellas provincias donde convive lo "indio", con lo "blanco" y lo mestizo. Santiago del Estero es la provincia del mestizaje.

Esta situación obliga al grupo docente a generar un proceso pedagógico acorde a esta realidad multicultural, garantizando, para ello, que el espacio de trabajo esté "liberado" de crítica, prejuicios, influencias, ejercicios de poder o requerimientos de obediencias. Esto es imprescindible para habilitar las voces de la diversidad, para que éstas resuenen, reverberen en la multiplicidad de relatos de identidad. 
La "diversidad dialogante" (concepto acuñado por la UNESCO, como parte de la riqueza cultural) es el camino apropiado (y muchas veces, doloroso) para el conocimiento, la comprensión, aceptación y convivencia pacífica, respetuosa y tolerante de lo diverso.

Escucharnos, comprendernos, respetarnos y tolerarnos. Sensibilizarnos, encontrarnos, conectarnos, conocernos, y aceptarnos como diferentes, pero también como iguales, en el sentido de que, lo humano, en su condición biológica y cultural, es siempre "unidad en la diversidad,... diversidad en la unidad" (Morín, 1999, p. 25).

\section{Identidad}

Esta experiencia, profunda, emotiva y vibrante, de la "diversidad dialogante", comienza el primer día de capacitación, con el reconocimiento de las producciones individuales -lo qué es capaz de hacer cada uno- expresado a través de relatos de vida, de supervivencia, de sustentabilidad individual, familiar o de una comunidad, de aprendizaje de técnicas o de su herencia ancestral, tanto para los procesos productivos de elaboración de objetos como los de la materia que los constituyen. Estos relatos ponen a la vista las identidades productivas locales como una parte importante de la identidad cultural.

"La historia narrada es un ingrediente esencial en la formación de la identidad ya que... sirven como instrumento cultural que permiten crear y recrear la idea de quiénes somos, qué queremos y quiénes son los otros" (Esteban, Nadal y Vila, 2008, p. 131).

El segundo día, salen a la luz, los múltiples relatos de identidad cultural provincial, que se van traduciendo y sintetizando en palabras clave que los representan: "Catarata de palabras que sin ningún orden, enuncian elementos naturales (paisajes, flora, fauna), comidas, fiestas, bailes, canto, música, próceres, edificios, monumentos, fábulas, etc." (Porrúa, Rueda y Vietto, 2009, p. 415). Estas palabras se van agrupando en bloques significativos y descomponiendo en sus cualidades esenciales, dando lugar a un primer sistema de signos/ palabras, que en su entramado comienzan a representar conceptos, soportes de identidades. Es a partir de estos relatos que los participantes se sensibilizan y comienzan a construir vínculos de afecto, esenciales para mantenerse unidos en el largo camino de la creación de su colección de objetos con identidad: "Debaten, disienten, confrontan o acuerdan. Comienza un ritual de socialización, de unión de individuos y grupo, que perdurará y se perfeccionará con el correr de la capacitación” (Porrúa, Rueda y Vietto, 2009, p. 415). Se inicia el proceso de articulación de personas y de sus identidades.

Queda así plasmada, en el primer seminario, una proto estructura, que ordenará la diversi$\mathrm{dad} /$ unidad en bloques o ejes significativos de la identidad provincial. Comienza a visualizarse el grado de independencia de los bloques y los puntos de una posible conectividad. El mapa de la identidad provincial -que muchas veces excede sus límites conectándose con otras provincias, como San Juan/ Mendoza o Formosa/ Chaco u otros países, como Formosa/ Paraguay, en identidades de carácter regional o transnacional- queda esbozado entre todos. Perfeccionarlo, legitimarlo y hacerlo propio dependerá del compromiso que cada uno asuma, en el proceso de construcción colectiva del discurso de identidad.

La didáctica puesta en juego parte de estas narraciones, como sistemas de signos y símbolos, promoviendo, a través de procesos de transferencia, el pasaje del lenguaje verbal/ 
narrativo, a lenguajes formales, propios de los objetos.

La Capacitación en Diseño busca brindar herramientas teórico-prácticas para desarrollar diseño con identidad como valor de diferenciación cultural y su codificación en lenguajes formales, materiales y técnicos. Estas acciones requieren de una metodología que comienza con los relatos verbales de temáticas de identidad y su paulatina traducción en imágenes gráficas, las que configuran "escenarios" de identidad. En éstos escenarios se esconden los repertorios morfológicos, simbólicos, materiales y técnicos que deberán ser analizados, codificados y sistematizados, para aplicar mediante procesos de transferencia a los objetos emergentes de este proceso de configuración.

Un objeto con identidad es aquel que puede distinguirse de otros objetos, pues sigue una serie de patrones formales, materiales y técnicos-productivos, engendrados en el territorio - por la gente que lo habita-y, por lo tanto, reconocidos como propios. El diseño con identidad es aquel que coloca entre las variables en juego, en los procesos de configuración de objetos, esos rasgos distintivos, que representados en repertorios formales, materiales y técnicos, se transfieren a los objetos. Como se verá en el siguiente punto, los instrumentos didácticos puestos en juego, para la configuración de la forma, cometido esencial del diseño como proceso, contendrán estos repertorios de identidad.

Es así que, en la Etapa 1, a lo largo de diez seminarios (o 160 horas de taller), desarrollados durante un año completo, el discurso de identidad va teniendo su correlato en un sistema de objetos con rango de "colección". Las colecciones se configuran desde la articulación de una diversidad de líneas y series de objetos que manifiestan aspectos parciales y relevantes de la identidad provincial.

Hacia el final de la capacitación, los relatos y subrelatos de identidad se van haciendo "polifónicos", desde un proceso de integración de las voces, de todos los relatores o participantes de la capacitación, que, a su vez, van dando forma, orden y estructura al discurso. (Bajtín, citado en Esteban, Nadal y Vila, 2008).

Desde el punto de vista estructural, este relato de identidad provincial, se constituye en la suma de sub relatos, coherentes con el territorio y sus habitantes, su historia y desarrollo cultural, social, económico, político, etc. Los subrelatos de identidad, no son, por tanto, visiones o variaciones posibles de lo mismo, son la manifestación de la diversidad, de las diferentes identidades que confluyen en el territorio provincial.

El discurso, por lo tanto, no es homogéneo, es de diversidad articulada. No está centrado y jerarquizado, es policéntrico y desjerarquizado. De la misma manera que la diversidad de voces, expresadas en múltiples relatos, se hace polifónica, su traducción a un sistema de formas, se hace, recíprocamente, polimórfico.

La colección, como organización formal compleja, propone la disonancia como una nueva forma de armonía. La diversidad, al ser inclusiva (y no excluyente), incluso de la global, emancipa (y no subordina), para construir (y no deconstruir) una identidad cultural propia, local, basada en la articulación de lo diverso.

La colección de objetos, como sistema de representación, comunicación e identificación, es el referente simbólico que vincula a las personas como colectivo, es el símbolo de su identidad colectiva y lo que las cohesiona generando un sentimiento de pertenencia y de apropiación, posesión. 
En general, si se observa el mapa de las colecciones provinciales (relatos de identidad provincial) y sus líneas internas (ejes relevantes del relato provincial), se verá cómo, determinados ejes temáticos, se repiten en todas la provincias, permitiendo establecer tres categorías englobantes, que refieren al Territorio, a la Celebración y/o a la Memoria. Estos ejes, se trasladarán, también, a las Colecciones nacionales "Argentina" y "Argentina en el Bicentenario".

El Eje del Territorio se ocupa de esa relación indisoluble que se da entre las comunidades y la tierra en las que habitan, dando lugar, en la acción que operan, a territorios más o menos humanizados. Integran este eje, líneas de identidad asociadas al Paisaje como concepto cultural y receptor de identidad. El Paisaje, en nuestro país, tiene una potencia particular, basado en la extensión, espectacularidad, diversidad (física, pero también de su flora y su fauna) y su productividad. Dependiendo de la provincia de que se trate, las colecciones pueden tener una o más líneas que representan una variedad de paisajes, como es el caso de las provincias patagónicas que comparten 3 tipos de paisaje característicos, la montaña, la estepa o meseta y el mar. En estas líneas el potencial del repertorio morfológico se concentra en el color y la textura, pero también en la síntesis formal de ese paisaje y de su flora y de su fauna local. Respecto a los materiales, se despliegan aquí los propios del territorio, lana, algodón, pelo de camélidos, arcillas, maderas, piedras semipreciosas, tintes naturales. Tal vez sean éstas las líneas que mejor sintetizan una estética basada en la comunión de los rasgos naturales y artesanales.

El Eje de la Celebración se constituye en los mitos y leyendas, en los rituales y fiestas populares y en la concentración de la vida urbana, donde la diversidad cultural se hace presente en la fuerza de la aglomeración y confrontación de lo diverso. Es el eje de identidad donde se produce, también, el mestizaje étnico, social y cultural. El mosaico, el collage, el patchwork, se constituyen como trama estructural, apropiada para vincular una gran variedad de formas, colores, texturas, materiales y técnicas, signos de lo heterogéneo, lo multicultural y de la pluriidentidad característica de todas las provincias argentinas. La articulación como lógica operacional, es apta, como se verá en el siguiente punto, para configurar objetos bajo el concepto de "Argentina articulada", línea de identidad nacional que reúne, como sistema combinatorio, a los objetos de las líneas provinciales que representan la diversidad provincial.

El Eje de la Memoria se constituye con los relatos que hacen referencia a hechos, sucesos y protagonistas, mitos de origen e identidad, que, siendo parte de la memoria colectiva, son traídos al presente como recuerdo, conmemoración o reconstrucción del pasado, contra el olvido y como símbolo de justicia o reparación histórica. La memoria se representa a través de signos creados culturalmente, como pueden ser, en el caso que nos ocupa, los objetos de indumentaria, textiles, vajillas, joyería, etc.

Todas las colecciones provinciales poseen líneas de identidad que refieren, directa o indirectamente, a la memoria de los pueblos originarios, que habitaban y habitan el territorio. Son ejemplos, las Líneas "Tehuelche" de la Colección Santa Cruz, "Mapuche" de la Colección Chubut, "Ser Huarpe" de San Juan, "Geométrica" de Chaco, "Oeste" de Formosa, "Omaguaca" de Jujuy, entre otras. La simbología propia de cada una de las culturas y sus tejidos particulares ancestrales en telar, constituyen la clave de su lenguaje, caracterizado 
por el contraste del fondo y la figura, la repetición de motivos construyendo guardas y tramas tradicionales, pero también, versiones contemporáneas, basadas en la innovación formal y técnica. Todas estas líneas provinciales, se mezclan en la línea "Ancestros" de escala nacional. La interacción de las diferentes simbologías, cuestión inusual, es su clave. Es a partir de esta actitud de mezcla que comienza a visualizarse una estética contemporánea, de raíz nativa, con toda la profundidad del mensaje, sin caer en operaciones de vaciamiento de significación. El espacio de la capacitación, del que participan las diversas comunidades indígenas, ha servido para habilitar la continuidad de procesos de generación formal, interrumpidos por la colonización. La seguridad y confianza que se va construyendo en el taller, también, posibilita los permisos para producir el mestizaje que emerge de la diversidad, de la interacción con los otros.

En el eje de la "Memoria" se incluye la Línea "Momentos de oscuridad/ momentos de claridad/ la sangre derramada", que compone junto a otras la Colección Bicentenaria. Su relato, conmovedor, intenso y profundo, nace limpio, con convicción, como reflexión colectiva, sin requerir confrontaciones, en una sesión de la que participaron "de pie", más de 400 capacitados. Los conceptos fueron aflorando de manera natural asociados a los símbolos patrios como momentos de luz (celeste y blanco), al dolor y luto como momentos oscuros (negro) y a la simbología indígena como la sangre derramada (roja sobre negro). La alternancia y repetición cíclica de estos tres conceptos/ momentos simboliza el proceso de gestación de la nación. Es un doloroso relato, donde conviven vergüenzas, heridas, deudas, culpas, resentimientos, pero, al hacerse "sinfónico", también es de esperanza y luz. De aceptación y reparación, si se quiere. Se transfiere a los objetos de indumentaria y joyería de manera contundente. Sobre tipologías básicas (babuchas, enteros y vestidos) se disponen bandas geométricas tejidas en telar indígena La línea se constituye en tres series de cuatro conjuntos cada uno. Las formas son austeras, simples y geométricas, para que el significado se exprese con fuerza, sin distracciones o imprecisiones. La serie "Momentos de Claridad" es celeste y blanca y evoca, en la claridad o la luz, de la bandera, de la escarapela, el germen incipiente de la nación. La serie "Momentos de Oscuridad" es de color negro compacto, como expresión de duelo nacional. El barracán, tejido por los hombres, es el tejido principal de esta serie. La serie "La Sangre Derramada" es la de los pueblos originarios y se expresa en prendas rojas y negras, constituidas por tejidos ancestrales, elaborados por mujeres y hombres del colectivo nacional. Lo impresionante es que, en estos tejidos no se distingue qué comunidad los tejió. Esto implica un dejar de lado las particularidades que los diferencian, para encontrarse, desde la simbología y la técnica, en un lugar común. En su elaboración, en el espacio mancomunado de los telares, tejían, por turnos, mujeres indias, blancas y mestizas.

La idea de sistema combinatorio de las colecciones provinciales, nacida de la propia lógica de la articulación, permitió visualizar el potencial de su mezcla. Ésta permite la multiplicidad de relatos de identidad nacional, a partir de la infinita variación combinatoria en torno a cinco conceptos: "Bicentenario" (con sus Momentos de Oscuridad y Momentos de Claridad), "Argentina Cruda", "Argentina Articulada", "Ancestros" y "Paisajes argentinos". Esta es la construcción intelectual de un discurso de identidad y de su estructura, que ordena los objetos como sistemas combinatorios, abiertos y polisémicos. El relato nacional Bicentenario se compone de cinco ejes de identidad, en los que se inscriben las múltiples 
líneas de identidad provincial de las diez colecciones, desarrolladas entre 2002 y 2011. La "Colección Argentina en el Bicentenario", presentada en el Palais de Glace (2010), en la Pasarela Nacional del Mercado de industrias Culturales de Argentina (MICA) y del Tecnópolís (2011), amalgama la identidad local, luego la regional y finalmente la nacional, desde una concepción federal, donde cada identidad local se articula, en la trama de la diversidad que somos.

\section{Articulación}

La colección de objetos con identidad local (de escala provincial o nacional) es el emergente material visible del proceso colectivo que construyen los participantes entre sí. Dicho proceso está basado pedagógicamente en el reconocimiento y la articulación estratégica de personas -con sus habilidades y saberes, por un lado y su diversidad cultural y social, por el otro-, los materiales, las formas de producción y los signos de identidad local.

La articulación fue la operatoria que nos permitió unir, enlazar, conectar, componer, montar, ensamblar, lo individual en lo colectivo y lo singular en lo plural. Vincular por articulación vale tanto para el sistema humano, como para el de identidades y el de los objetos, incluyendo dentro de este último, la articulación de variables, como puede ser la diversidad de técnicas, que cada participante aporta a la capacitación. La articulación se da siempre en una relación aditiva de acercamiento, de proximidad de personas o cosas diversas, que entran en relación sin perder sus singularidades, sus diferencias. Nunca busca integrar, pues la integración sigue el procedimiento de la homogeneización, teniendo que borrar, para ello, las diferencias en aquello que se busca integrar, extendiendo las cualidades de uno sobre otro, eliminando las propiedades de uno, poniendo en desventaja y tomando partido, en definitiva, por uno sobre otro $\mathrm{u}$ otros. La articulación no busca asimilar para borrar las diferencias, por el contrario, las pone de manifiesto. Si en la integración prevalece la unidad como principio organizacional, en la articulación, en cambio, se impone el de la diversidad. Uno es cerrado y el otro es abierto. La articulación se da en un espacio de encuentro de lo diverso. Está en su esencia la variación, la posibilidad combinatoria para una permanente reconfiguración, por lo tanto los objetos, las colecciones de objetos, que surgen desde estos procesos de articulación son abiertos, flexibles, adaptables y dinámicos. Es a partir de esta lógica de articulación que los procesos de mestizaje son posibles. Esto se produce cuando la articulación, como enlace, queda desbordada o transformada desde afuera, por una suerte de “...perturbación nacida del encuentro con el otro, que introduce la desregulación y la innovación en la totalidad.” (Laplantine y Nouss, 2007, p. 211).

El mestizaje es además un proceso que recompone un nuevo tipo de totalidad, basado en la diferencia. Trasciende lo únicamente local y particular para construir un singular y universal. Procede globalizando de una manera diferente, no homogeneizando, asociando, mezclando lo heterogéneo, en su contexto.

La articulación como estrategia, promueve, entonces, el enlace de lo diverso e invita al desarrollo de procesos de mestizaje (de personas, en primer término, pero luego, consecuentemente de sus identidades, de sus técnicas, de sus lenguajes, de sus procedimientos, etc.). Invita y no obliga o compulsa, decíamos, porque el mestizaje se da espontáneamente 
en un momento de sincretismo que no puede forzarse, mezclando lo diferente, enlazando lo dividido, de tal manera, que lo que se genera es otra cosa y es nueva. Tiene ciertamente un carácter mágico o de "realismo mágico" (García Marquez) o de "real maravilloso" (Carpentier), pues se presenta como alteración de la realidad. Lo mestizo, como lo define Laplantine y Nouss, está "entre" dos opuestos o confrontados: lo heterogéneo y lo homogéneo; el orden y el desorden; lo compuesto y lo descompuesto; lo local y lo global; lo ancestral y lo moderno; lo artesanal y lo industrial; el arte, la artesanía y el diseño. No es ni el uno ni el otro, es una nueva conjunción que tiene algo de todos ellos, sin ser ninguno, ni tender a serlo y, por lo tanto, es otra cosa, con entidad nueva y propia. Es bilingüe, pero habla su propia lengua. En términos del diseño de objetos, un objeto mestizo, surge de un proceso de creación (de su forma, de su técnica, de su lenguaje, de su estética y de su ética), que es mestizo.

Hay toda una serie de procedimientos operacionales que son aptos para articular lo diverso e incluso pueden ser el medio para el mestizaje. Lógicas de organización formal, como el collage, el patchwork, operadas por ensamblado, acercamiento, proximidad, entrecruzamiento, entrelazamiento, son la base del mestizaje de lo heterogéneo, de lo compuesto y múltiple, de la discontinuidad y la disonancia, del desorden que se ordena en la reunión de los fragmentos significativos, en estructuras, polimórficas, policéntricas y polisémicas. El fragmento es la unidad con la que se opera y el mestizaje es el efecto final de estas operatorias.

El diseño, como actividad relacional por excelencia, promueve la configuración objetos desde la articulación de variables. La propuesta pedagógica a través de su didáctica, coloca, a la vista de todos los participantes, el proceso que el pensamiento creativo elabora en el inconciente, en formato de tabla de doble o triple entrada. Llamamos a este instrumento la "matriz morfológica". El común denominador de los métodos de creatividad consiste en la exploración, azarosa y sistemática, de un espacio combinatorio, conformado por el conjunto de dimensiones relevantes del problema. La matriz morfológica es, por analogía, la representación de ese espacio. La exploración combinatoria aleatoria de los atributos enlistados en las celdas de la matriz es el procedimiento articulatorio para la creación de objetos con identidad, democratizado para el conjunto de los participantes.

En esta matriz están contenidas, tanto las variables intrínsecas (propias del objeto: forma, función, materialidad, técnica, significado), como los repertorios morfológicos que surgen de los procesos de traducción de los relatos de identidad verbal. También, el conjunto de las operaciones para la articulación y el mestizaje de partes en el todo.

Así como hay una matriz morfológica como soporte de nuevos objetos, hay una matriz productiva anclada en la matriz humana que se va configurando al paso de los seminarios. Estas tres matrices actúan articuladamente.

En la matriz morfológica hay variables de objetos por venir. En la productiva las variables son las habilidades técnicas (sean estas ancestrales o contemporáneas, indígenas, europeas o mestizas) y la materialidad local en relación con los objetos creados. En la humana se va construyendo, la grupalidad, la colectividad como fuerza, el respeto desde la interacción de las diferencias, la dependencia estratégica entre miembros del grupo, el valor de la creatividad, autoría, autoestima colectiva, la ruptura de las limitaciones personales, la identidad en los objetos que es la identidad -o suma de identidades- del grupo, la colección de objetos y de personas como sistema indisoluble. 
Como bien expresa García Canclini, los procesos de homogeneización de la cultura, de los parámetros de belleza y de los estéticos, han fracasado pues plantean un patrón excluyente, a contramano de la diversidad que somos. En los procesos que fomentan la diversidad se aceptan las diferencias. No para homogeneizarlas, si no para respetarlas y construir desde lo diverso, un nuevo todo, que presenta un nuevo criterio de armonía, basada en la disparidad, la disonancia y el contraste de lo múltiple. "Enfrentando a la totalidad como "conjunto acabado" (Bataille), el mestizaje sería la totalidad fallada (o tachada), la reivindicación de "un defecto de conjunto: el cambio que revela una realidad móvil, fragmentada, inasible...". (Laplantine y Nouss, 2007, p. 681).

De la conducta articulatoria y de los procesos de mestizaje, emanan nuevos parámetros de belleza, basados en una nueva estética de la diversidad, que define a la identidad local, que es, a la vez, contemporánea, en confrontación con la uniformidad de la estética internacional/ global.

El mestizaje no es solamente una creación de nuevas diversidades a partir del encuentro; en el proceso planetario éste se vuelve producto y productor de religazón y de unidad. Introduce la complejidad en el corazón de la identidad mestiza (cultural o racial) (Morín, 1999, p. 37).

La estética global promueve, además, el requerimiento de la novedad permanente. Eso que Morín llama la “...inanidad de la innovación (entre más cambia más es la misma cosa).” (Morín, 1999, p. 44). Inanidad que se suma a la vacuidad, soportada en procesos de pérdida de significación de la identidad, necesarios para que las producciones y bienes culturales locales, queden subsumidos y enrasados en la lógica de homogeneización.

Entendiendo lo "local" como el área geográfica en donde "las relaciones sociales cotidianas se producen en un contexto de proximidad" (Mazorra, Filippo y Schlesser, 2004), que se condensan al interior de esos espacios y que posibilitan, desde su interior, el desarrollo, la expansión y mejora de la realidad social, económica, cultural y política, sin depender de ayuda externa. La identidad local se construye en el territorio. Éste debe ser visto como una matriz organizativa de las interacciones socio- culturales de sus habitantes, con sus instituciones, con los recursos naturales medioambientales, la cultura del trabajo y las redes sociales emergentes, todo ello condicionante y determinante de las diferentes lógicas económicas y técnico- productivas, que en ese espacio son coherentes y viables.

El diseño con identidad local, no puede más que ajustarse a estos enunciados. Debe ser respetuoso de la diversidad cultural y del medio ambiente y colaborar en el objetivo de promover una economía local no dependiente. El diseñador que se inscribe en esta ideología, se articula en la matriz territorial, como un actor más, entre muchos otros. Lo mismo vale para un colectivo de diseño, como lo es la Red Identidades Productivas, con la salvedad (respecto de un diseñador independiente) de que, además, conforman, todos juntos, una red social y productiva. La articulación del diseñador en la matriz territorial hace la diferencia, respecto del diseñador tradicional, formado para actuar en el mundo global, bajo pautas que hacen homogénea la cultura, la identidad, el lenguaje formal de los objetos y el sistema tecnológico. 
Como contrapartida al lenguaje uniforme y ajeno de la globalización, sostenido por el sistema moda, los procesos de diseño colectivo basados en la articulación de la diversidad promueven una nueva estética acorde con esta lógica operativa, que emana, del enlace, el encuentro de dos o más cosas diferentes. Y es que de la interacción de identidades, formas, lenguajes y técnicas, surgen objetos en donde lo heterogéneo articulado es su clave. En el núcleo Identidad, ya han sido sintetizadas las particularidades de esta estética de la confrontación. La síntesis formal puede ser, en un extremo, geométrica y disonante como en el Eje de identidad "Argentina Articulada", en virtud de la discrepancia formal, material, técnica y de significado de los elementos/ fragmentos característica de la pluralidad en juego. En el otro extremo, el efecto puede ser de concordancia, si se combinan simultáneamente, por ejemplo, materiales naturales, técnicas artesanales y paletas de colores que tienden a suavizar el efecto articulatorio, como en el Eje "Paisajes Argentinos", cuya característica atemporal y orgánica, propia del paisaje, se traslada a la forma de los objetos. La articulación y el mestizaje proponen operaciones que -enfrentadas al procedimiento de subordinación- permiten generar un todo nuevo, nacido del encuentro de la diversidad y de la heterogeneidad del propio territorio, inclusivo de lo local y lo global, de lo ancestral y lo contemporáneo, de lo permanente y de lo efímero, equilibrando lo que está desequilibrado, fomentando una nueva sustentabilidad humana, basada en la equidad. No se trata ya de tener más, si no de ser mejores.

\section{Diseño Colectivo}

La Capacitación en Diseño es una propuesta pedagógica que permite enseñar diseño a un grupo heterogéneo de personas, en edad, educación, origen, identidad, religión, etc., para generar entre todos, una colección de objetos con identidad local.

Desde el punto de vista del proceso que se recorre, el inicio se corresponde, como ya se ha visto, con el enunciado, en el $1^{\circ}$ seminario, de los relatos de identidad y su traducción a un repertorio formal, material y técnico. La información que se genera en esta práctica, va volcándose en las matrices morfológicas, conjuntamente con las variables intrínsecas y extrínsecas del objeto a diseñar y las particularidades del grupo humano, sus saberes y habilidades singulares que, en la combinatoria estratégica, se harán colectivas.

Las matrices morfológicas son el instrumento didáctico generado por este grupo docente y perfeccionado durante más de dos décadas. Si originalmente constituyeron, simplemente, una técnica creativa para la exploración múltiple de alternativas, hoy es una pieza clave de una propuesta pedagógica con desarrollo teórico propio. La matriz morfológica es el espacio en el que concurren la totalidad de los elementos y actores que entran en juego en un proceso de organización de la forma, de la identidad local y de la grupalidad. Ya se ha dicho que hay un correlato entre el sistema de objetos, el sistema humano y el sistema de identidad, por lo tanto, también, de sus procesos generativos- organizativos. Tres sistemas que pueden, en la matriz morfológica, desglosarse en sus variables particulares, las que a su vez pueden caracterizarse desde cualidades múltiples posibles. Se suma a estos tres sistemas un cuarto, el sistema operatorio, que permite establecer las relaciones entre variables, su combinatoria. Ya que nuestro objetivo es el diseño colectivo de objetos con 
identidad, cuyo sello distintivo es la diversidad, se trabaja pedagógicamente en la generación de una conducta de articulación de lo heterogéneo, que se transporta a los objetos, su realidad material y técnica. Lo diverso comienza a convivir, poniendo en evidencia el proceso de intercambio y articulación de las individualidades en un todo común.

Los talleres creativos, haciendo uso de las matrices morfológicas, funcionan como laboratorios para la exploración colectiva de ideas/ eje para el desarrollo de objetos posibles. Las ejercitaciones, de fuerte carácter experimental, creativo y propositivo, intentan captar los intereses de los participantes y poner en juego sus habilidades para manipular, transformar y actualizar los signos de identidad, las formas, los materiales y las técnicas, en objetos conocidos.

Estos talleres nos permiten reconocer a los participantes en acción y relación, imaginar prospectivamente lo que son capaces de hacer, definir la potencialidad del grupo, para ajustar el proyecto en busca del máximo impacto.

El rol de los docentes, cuando se enseña diseño colectivo, es de articulación de habilidades. Para ello deben conocerse las particularidades de cada uno e ir conectando esas habilidades estratégicamente, buscando en esta conectividad una manera nueva e inesperada. Los saberes técnicos ocupan un lugar preferencial en el sistema articulatorio de habilidades para la innovación.

Para ello, la didáctica debe posibilitar la expresión de todos, eliminar los prejuicios, estimular para proponer, elegir, combinar y construir. Cada trabajo se desarrolla en torno a varias consignas o momentos. Esto permite la rotación de trabajos, de tal manera que el que desarrolló individualmente una consigna, en la siguiente le tocará actuar sobre la propuesta de un compañero. El grupo se fortalece con la circulación de los trabajos, la multiplicidad de miradas, la diversidad de conocimientos, y de habilidades técnicas. Esta práctica conjunta para el diseño colectivo, permite quebrar el sentimiento de autoría personal y abrir las puertas de una experiencia de producción grupal, en la configuración del sistema de objetos o colección.

El diseño es colectivo, pues la autoría no está centrada en las capacidades de un individuo, sino que se sostiene en la articulación de la diversidad de capacidades de todos los participantes.

En el $8^{\circ}$ seminario se colocan la totalidad de los trabajos en la pared, agrupándolos, por similitud, en torno a los diversos ejes que constituirán el sistema de de objetos con identidad local, los que se encadenan y sistematizan en un argumento global. Quedan definidos los objetos que integrarán cada línea y los requerimientos materiales y técnicos para la materialización de los prototipos.

Aquellos primeros agrupamientos en torno a la identidad, se van rompiendo en la dinámica de la creación colectiva de objetos, para reagruparse, finalmente, como grupos productivos específicos, capaces de materializar los objetos.

En el $9^{\circ}$ y $10^{\circ}$ seminario se organizan los grupos en torno a las líneas de identidad definidas y se comienza a desarrollar el ajuste formal y técnico para la producción de los objetos que serán presentados en el evento final. Este evento tiene la particularidad de hacer público, no sólo, el sistema de objetos diseñados, sino, además, el argumento de identidad que los soporta y a sus autores colectivos. Su éxito puede medirse por el nivel de identificación que se logre en los espectadores. 


\section{Red}

La Etapa 2, contempla estrategias de generación de nuevos ejes de identidad de escala nacional y la articulación y combinación de los sistemas de objetos provinciales, para desarrollar las Colecciones interprovinciales. A su vez, por su carácter de usina o espacio para la experimentación colectiva, este taller "mancomunado" es de germinación de nuevos conceptos, procesos, estrategias colectivas que tiendan a articular y potenciar los resultados desde la interacción provincial.

La red interprovincial, conformada por 680 capacitados en diez provincias, se propone como espacio de interacción, intercambio, síntesis y crecimiento para la integración de los grupos capacitados, de sus respectivas colecciones, de sus identidades provinciales y de las habilidades técnicas específicas, para la elaboración de proyectos más complejos tendientes al desarrollo de diseño colectivo con identidad nacional, la producción, la promoción y comercialización de los objetos de manera mancomunada, en formatos genuinos, autogestionados, autónomos, posibles y autosustentables.

El taller interprovincial, especialmente conectivo, tiene su antecedente en encuentros mancomunados originados en le necesidad de encontrar a grupos provinciales que recibían capacitación en diferentes puntos de una provincia. Chubut fue la provincia que requirió estratégicamente, este tipo de encuentros. Los grupos capacitados en Esquel, Comodoro Rivadavia y Trelew fueron desarrollando sus discursos de identidad en relación con sus territorios inmediatos y, luego, trasladándose todos a un punto neutral, la confrontaron y articularon en una identidad provincial común. Esta experiencia dio forma a nuevos procesos, más complejos, no sólo en lo pedagógico, también en los aspectos logísticos y organizativos de este programa.

La visualización de los efectos del encuentro de grupos, provenientes de diferentes provincias capacitadas, dio origen al primer encuentro interprovincial en el Correo Argentino en mayo de 2005, en la Ciudad de Buenos Aires. Allí concurrieron los grupos provinciales de La Pampa, Santa Cruz, Chubut y San Juan, con sus respectivas colecciones, las que fueron mostradas públicamente y, a su vez, como primer hecho participativo, abierto a la comunidad, una serie de talleres convocaban al público a participar en la configuración de nuevos objetos en torno a las técnicas de sus artesanos.

Estas experiencias hicieron posible la constitución de una red de personas de escala más amplia, sus identidades, locales y regionales, y la necesidad de comenzar a conectarlas. La idea de una colectividad interprovincial ya estaba fundada y la apertura de nuevos procesos sobrevino naturalmente. La colectividad fue tomando forma, natural y espontáneamente, en un esquema de red, organización compleja y abierta, apta para el crecimiento orgánico y las relaciones horizontales y desjerarquizadas, flexible y autoadaptable al cambio, receptora de la heterogeneidad, actúa desde el pensamiento múltiple y se orienta a crecer en beneficio de todos por igual.

El encuentro mancomunado se produce en el Complejo Chapadmalal de Mar del plata, sede de la Universidad, dos veces por año, en dos seminarios de 32 horas cada uno, dictados en cuatro días consecutivos. En este gran taller interprovincial se genera la "Colección Argentina del Bicentenario", se formaliza la Red Identidades Productivas y germina el concepto de Series 1 x 10 . 
El proyecto Series 1 x 10, consiste conceptualmente, en la elaboración de series integradas por productos asimilables a partir de una o más pautas comunes: rubro, tipología, técnica, material, complejidad, escala, precio e identidad: 1 producto por provincia. Este nuevo enunciado, intenta, desde su carácter metafórico, dar cuenta del sentido de una red productiva que se autocompensa, solidariamente, entre todos.

Primer paso a una producción y comercialización interprovincial, solidaria y auto sustentable entre todos. Este nuevo proyecto, requirió de una logística organizacional y comunicacional que pudiera sortear las distancias entre las 10 provincias.

El facebook Red Identidades Productivas es una plataforma de comunicación, proyección y organización de la producción, del colectivo nacional.

Tanto el proceso de configuración de objetos de la colección (diseño colectivo), como el de configuración del grupo humano (colectividad) van auto construyéndose apoyados en el concepto de "articulación en red" como esquema apropiado para establecer relaciones múltiples. La red se va construyendo y constituyendo a la par del sistema de objetos y, según ha demostrado la experiencia, al final de este proceso, la unidad y la sistematicidad son cualidades, tanto de los objetos que componen la colección, como de los sujetos que la diseñan, la producen y comercializan.

\section{Notas}

1. Co Autores: Marta Rueda, Marco Bernich, Hernán de Filippis, Cristhian Ruth Moyano, Sol Deangelis, Guillermo Isasmendi, Lucía Ducombs (Miembros del Grupo de Extensión "CULTURA Y DISEÑO" (OCA 0333/ 03) de la Secretaría de Extensión de la Facultad de Arquitectura Urbanismo y Diseño, de la Universidad Nacional de Mar del Plata. Desarrollan, entre otros programas, el "Plan de Capacitación de Diseño para la Producción", enmarcado en el Programa Identidades Productivas de la SCPN).

\section{Referencias Bibliográficas}

Bonsiepe, G. (1995). Del objeto a la interfase. Mutaciones del diseño. Buenos Aires: Ediciones Infinito.

Esteban, M.; Nadal, J. M. y Vila, I. (2008). Revista digital Glossa, Articles Volume $4 \mathrm{~N}^{\circ} 1$ : La construcción narrativa de la identidad a través del conflicto y la ventrilocuación. Disponible en: http://bibliotecavirtualut.suagm.edu/Glossa2/Journal/dec2008/LA-CONST RUCCI\%C3\%93N-NARRATIVA-DE-LA-IDENTIDAD.pdf

García Canclini,N.(2005).Todostienen cultura: ¿quiénes pueden desarrollarla?Conferencia para el Seminario sobre Cultura y Desarrollo, en el Banco Interamericano de Desarrollo, Washington, 24 de febrero de 2005. Disponible en: http://www.iadb.org/biz/ ppt/0202405canclini.pdf

(1999). La globalización imaginada. (4º edición 2008). Argentina: Editorial Paidós.

Laplantine, F.; Nouss, A. (2007). Mestizajes. De Arcimboldo a zombi. Argentina: Ed. Fondo de Cultura Económica de Argentina. 
Macas, L. (2001). Diálogo de culturas: hacia el reconocimiento del otro. Revista Yachayku$n a$, No2, diciembre del 2001 Quito, Ecuador. Revista Semestral del Instituto Científico de Culturas Indígenas, ICCI. Disponible en: http://icci.nativeweb.org/

Morin, E. (1999). Los siete saberes necesarios para la educación del futuro. UNESCO. Disponible en: http://www.unmsm.edu.pe/occaa/articulos/saberes7.pdf

Porrúa, M.; Rueda, M. y Vietto, C. (2009). Didáctica para la creatividad con identidad. Una herramienta social para la producción. (Pág. 409 a 419). En Fiestas y Rituales. Actas del $\mathrm{X}^{\circ}$ Encuentro Latinoamericano de Patrimonio Inmaterial. Lima, Perú Colombia: Editor John Galán Casanova. Disponible en: http://es.scribd.com/doc/26849143/Fiestas-y-Rituales-Actas-del-X-Encuentro-Latinoamericano-de-Patrimonio-Inmaterial

Remoury, B. (2005). Marcas y relatos. La marca frente al imaginario cultural contemporáneo. Barcelona: Editorial Gustavo Gili.

UNESCO. (2005). Convención sobre la protección y Promoción de la Diversidad de la Expresiones Culturales. París: Editado por UNESCO. Disponible en: http://unesdoc. unesco.org/images/0014/001429/142919s.pdf

Summary: Collective Design, Identity, Diversity, Articulation and Network are the keys that identify the Productive Identities Program, developed by the National Ministry of Culture, which, jointly with the Design Training Program: production of networks to enhance resources, projects and identities, developed by the Universidad Nacional de Mar del Plata, promote, since 2002, the development of groups dedicated to the collective design and production of object systems, which are carriers of cultural identities, with the rank of collection in the provincial and / or national level.

Key words: articulation - culture - collective design - diversity - education - identity network.

Resumo: Design Coletivo, Identidade, Diversidade, Articulação e Rede, são as chaves que identificam ao programa Identidades Productivas, da Secretaria de Cultura da Nação, que, solidariamente com o "Plan de Capacitaçao em Design: produzir redes para potenciar recursos, projetos e identidades", da Universidade Nacional de Mar del Plata, promovem, desde 2002, o desenvolvimento de grupos dedicados ao design e produção coletiva de sistemas de objetos, portadores de identidades culturais, com categoria de coleção provincial e/ou nacional.

Palavras chave: articulação - cultura - design coletivo - diversidade - educação - identidade - rede. 